Original Research Paper

\title{
Blood-Circulating Type 2 Follicular Helper T Cells in Pediatric Allergy Patients
}

\author{
${ }^{1}$ Masaaki Hamada, ${ }^{2}$ Yoshihiko Sakurai and ${ }^{3}$ Tomohiro Takeda \\ ${ }^{1}$ Department of Pediatrics, Yao Municipal Hospital, Yao, Japan \\ ${ }^{2}$ Department of Pediatrics, Matsubara Tokushukai Hospital, Matsubara, Japan \\ ${ }^{3}$ Department of Clinical Laboratory Science, Kansai University of Health Sciences, Kumatori, Japan
}

\author{
Article history \\ Received: 10-01-2020 \\ Revised: 27-04-2020 \\ Accepted: 19-05-2020 \\ Corresponding Author: \\ Tomohiro Takeda \\ Department of Clinical \\ Laboratory Science, Kansai \\ University of Health Sciences, \\ Kumatori, Japan \\ Email: t-takeda@kansai.ac.jp
}

\begin{abstract}
Pediatric allergic diseases are primarily caused by an IgEdependent immunological reaction. Despite studies reporting the involvement of $\mathrm{T}$ follicular Helper $(\mathrm{TfH})$ cells, especially type $2 \mathrm{TfH}$ cells, in class-switching to IgE production in B cells, TfH subset skewing in peripheral blood in pediatric allergy patients remains to be elucidated. This study aimed to investigate the possible involvement of type $2 \mathrm{TfH}$ cells in the pathogenic mechanism underlying pediatric allergic diseases. We analyzed TfH subsets (type 1, type 2 and type 17) in peripheral blood from pediatric patients with (allergy group, 35 patients) and without (non-allergy group, 26 individuals) allergic diseases via flow cytometry to determine the percentage of each $\mathrm{TfH}$ subset in the total $\mathrm{TfH}$ cell repertoire. Furthermore, the eosinophil percentage and serum total IgE and Thymus and Activation-Regulated Chemokine (TARC) levels were measured. No significant differences were observed in sex and age between the allergy and non-allergy groups. Since IgE levels were significantly higher in the allergy group than in the non-allergy group, no significant overlap was observed in the number of patients in the allergy and non-allergy groups. Although the total IgE and TARC levels and the eosinophil percentage were significantly higher in the allergy group than in the non-allergy group, the TfH subset analysis did not display a significant skewing of specific $\mathrm{TfH}$ subset cells. These results suggest the occurrence of either limited changes in peripheral blood TfH cells or the involvement of the immune cell subtype TfH13 in pediatric allergic diseases.
\end{abstract}

Keywords: Flow Cytometry, T Follicular Helper Cells, Immunoglobulin E, Peripheral Blood

\section{Introduction}

Allergen-specific Immunoglobulin E (IgE) plays a crucial role in allergic reaction and conditions such as food allergy, atopic dermatitis and asthma (Illi et al., 2006; Kasperkiewicz et al., 2018; Waserman et al., 2018). Since IgE levels in patients with allergic diseases remain elevated for a long period, the detailed $\operatorname{IgE}$ production-promoting mechanism has been previously investigated. Allergen-reactive type 2 helper $\mathrm{T}$ (Th2) cells are considered to be involved in the activation and recruitment of IgE antibody-producing B cells, because class-switching to IgE production in B cells requires Th2 cells to secrete cytokines IL-4 and IL-13 (Lebman et al., 1988; Poulsen and Hummelshoj, 2007). However, recent studies revealed that $\mathrm{T}$ follicular Helper (TfH) cellswhich are one of the CD4 $\mathrm{T}$ helper cell subsets in the germinal center of $\mathrm{B}$ cell follicles and in circulating blood (Nurieva et al., 2009)-play a key role in IgE production induced by $\mathrm{T}$ cell-dependent immune responses (Harada et al., 2012; Vijayanand et al., 2012; Kobayashi et al., 2017). TfH cells are a major source of IL-4 and they also secrete IL-2 (Kubo, 2017). Production of IL-4 in TfH cells is regulated through a different mechanism than Th2 cells (Kubo, 2017). Three subsets of TfH cells (type 1, type 2 and type 17 TfH cells; TfH1, 
$\mathrm{TfH} 2$ and $\mathrm{TfH} 17$, respectively) generate type-specific cytokines, regulate antibody production via B cells and are present in circulating blood (Morita et al., 2011). Recent studies have reported that circulating $\mathrm{TfH}$ cells contain long-lived memory cells, which are also known as blood memory TfH cells (Ueno et al., 2015). Although blood memory TfH1 cells cannot support naïve B cells, blood memory $\mathrm{TfH} 2$ cells induce $\mathrm{IgG}$ and IgE secretion and TfH17 cells stimulate IgG and IgA secretion (Morita et al., 2011).

Previous studies have reported a skewing or increase in the number of blood-circulating $\mathrm{TfH}$ cells in patients with bronchial asthma, atopic dermatitis and eosinophilic nasal polyps (Gong et al., 2014; 2018; Szabo et al., 2017; Zhang et al., 2016). Furthermore, a recent study reported that polarization toward $\mathrm{TfH} 2$ cells in asthma patients (Gong et al., 2016) suggests the involvement of $\mathrm{TfH} 2$ cells in the pathogenesis of allergic diseases and corresponds to the proposed function of blood memory $\mathrm{TfH} 2$ cells.

Immune function and $\operatorname{IgE}$ generation gradually increase in the course of growth. Allergic diseases often develop sequentially in childhood, which is classically known as the atopic march. In this condition, more than one disease often coexists (Aw et al., 2020). Furthermore, allergic diseases present distinct clinicopathological characteristics during childhood and adulthood (Brunner et al., 2018; Larsen, 2000; Izquierdo-Dominguez et al, 2017). Hence, although pediatric allergies have unique characteristics, it remains unclear whether $\mathrm{TfH}$ cells, especially $\mathrm{TfH} 2$ cells, are involved in pediatric allergies. Therefore, the present study aimed to determine whether blood-circulating TfH subset shift towards IgE production in pediatric patients with allergic diseases.

\section{Materials and Methods}

\section{Study Populations}

Our study populations were divided into allergy [patients with allergic diseases, $n=35$ (male, 24; female, 11 ), age, $66.89 \pm 8.30$ (months)] and non-allergy (control) [patients without allergic diseases and healthy children, $n$ = 26 (male, 14; female, 12), age, 58.42 \pm 12.77 (months)] groups. The clinical conditions of both groups are summarized in Fig. 1.

Allergic diseases were diagnosed by qualified allergy specialists in accordance with appropriate clinical criteria (Arakawa et al., 2017; Ebisawa et al., 2017; Saeki et al., 2016); however, disease severity was not considered. Written informed consent was obtained before blood collection from all participants included herein. All procedures involving human participants were approved by the Yao Municipal Hospital Ethical Committee, the Tokushukai Ethical Committee and the Kansai University of Health Sciences Ethical Committee and in accordance with the ethical standards of the 1964 Helsinki Declaration and its later amendments or comparable ethical standards.

\section{Laboratory Tests}

Peripheral blood testing and biochemical examination were performed. For eosinophil measurements, eosinophil percentage (Eo\%) was used owing to an altered white blood cell count during childhood. To measure serum Thymus and Activation-Regulated Chemokine (TARC) levels, a chemiluminescent enzyme immunoassay was conducted using the HISCL system (Sysmex, Hyogo, Japan) with a TARC assay kit (Shionogi, Osaka, Japan) in accordance with the manufacturer's instructions. TARC, a small cytokine belonging to the $\mathrm{CC}$ chemokine family, is associated with the induction of chemotaxis in T cells, particularly Th2 cells, by binding to the chemokine receptor CCR4. Total serum IgE levels were measured using the Phadia ImmunoCAP-System (Phadia, Uppsala, Sweden) in accordance with the manufacturer's instructions.

\section{Flow Cytometric Analysis}

Whole peripheral blood cells were stained at $4{ }^{\circ} \mathrm{C}$ for 30 min using combinations of the following antibodies: Peridinin Chlorophyll protein-Cyanin5.5 (PerCpCy5.5)-Conjugated anti-CD3 (BD Biosciences, Tokyo, Japan), Phycoerythrin Cyanine 7 (PE-Cy7)-Conjugated anti-CD4 (BioLegend, Tokyo, Japan), allophycocyanin cyanine 7 (APC-Cy7)-conjugated anti-CD45RA (BioLegend), phycoerythrin-Texas Red-X (ECD)conjugated anti-CD8 (Beckman Coulter, Tokyo, Japan), Alexa Fluor 488 conjugated CXCR5 (BD Biosciences), Phycoerythrin (PE)-conjugated anti-CCR6 (BD Biosciences), Allophycocyanin (APC)-conjugated CXCR3 (BD Biosciences) and isotype controls (BD Biosciences). Thereafter, red blood cells were lysed using the IOTest 3 Lysing Solution (Beckman Coulter). After incubation for $15 \mathrm{~min}$ at $25^{\circ} \mathrm{C}$, the cells were washed once with phosphate-buffered saline containing $1 \%$ bovine serum albumin. Dead cells were gated after staining using a DRAQ7 far-red fluorescent live cell impermeant DNA dye (Beckman Coulter). The percentages of $\mathrm{CXCR}_{+} \mathrm{CXCR}^{+} \mathrm{CCR}^{-}$(Tfh1), $\mathrm{CXCR}^{+}{ }^{-} \mathrm{XCR}^{-} \mathrm{CCR}^{+}$(Tfh17) and $\mathrm{CXCR}^{+} \mathrm{CXCR}^{-}{ }^{-} \mathrm{CCR} 6^{-}$(Tfh2) cells were enumerated after gating for $\mathrm{CD}^{+}, \mathrm{CD}^{+}, \mathrm{CD}_{4} 5 \mathrm{RA}^{-}$and $\mathrm{CXCR}^{+}$ (Fig. 2). Data were acquired using a Gallios flow cytometer (Beckman Coulter) and Kaluza software (Beckman Coulter) was used for data analysis. 
A

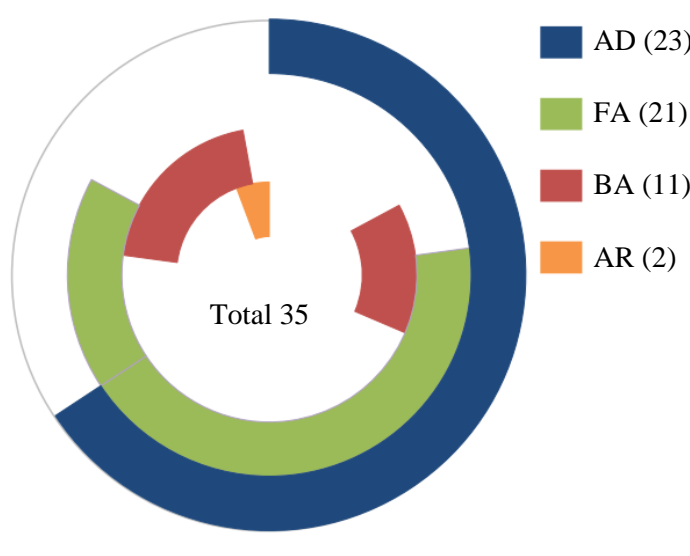

B

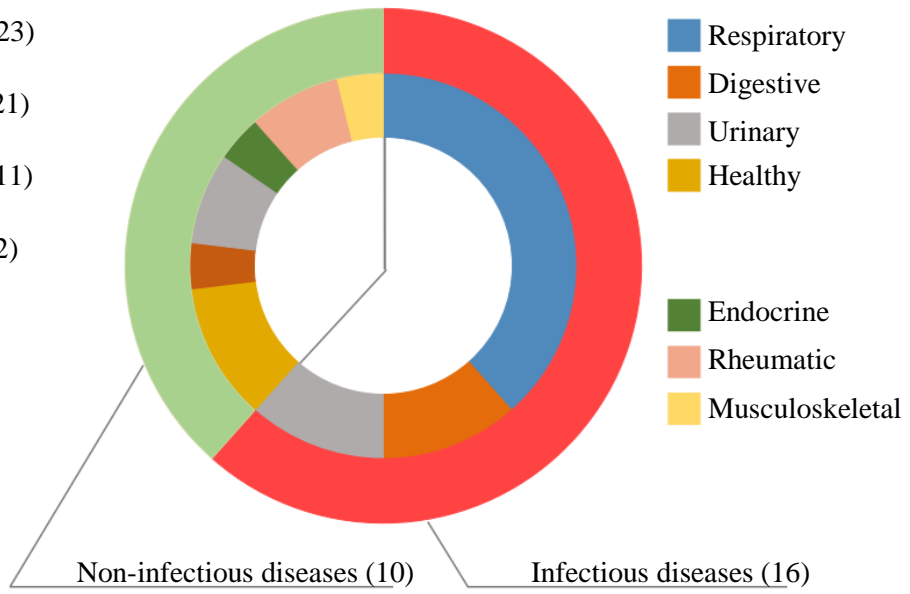

Fig. 1: Clinical conditions of study populations. (A) Allergic diseases include atopic dermatitis (AD; $n=23$ ), food allergy (FA; $n=$ 21), asthma (BA; $n=11$ ), allergic rhinitis (AR; $n=2$ ) (each number includes overlaps). (B) Control group includes healthy children $(n=3)$ and patients with non-infectious diseases $(n=7)$ and infectious diseases, such as respiratory tract $(n=10)$ digestive $(n=3)$ and urinary tract infections $(n=3)$.

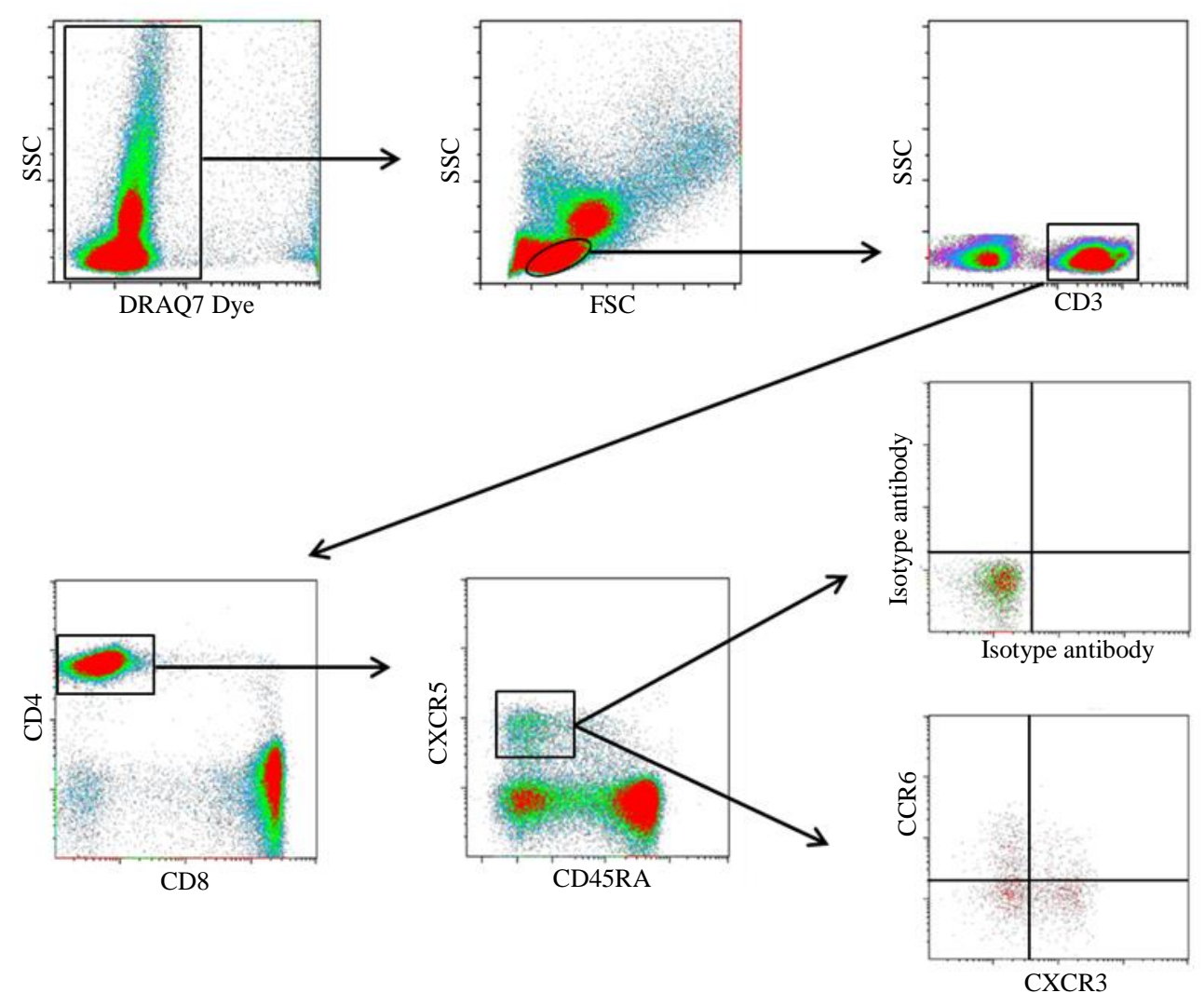

Fig. 2: Peripheral Blood Mononuclear Cells (PBMCs) were analyzed for their uptake of DRAQ7 to determine dead versus live cells. Subsequently, DRAQ7-negative live PBMCs were gated for lymphocytes (SSC vs FSC). The lymphocyte gate was further analyzed for their expression of $\mathrm{CD} 3, \mathrm{CD} 4$ and $\mathrm{CD} 8$. Thereafter, $\mathrm{CD}^{+} \mathrm{CD}^{+} \mathrm{CD}^{-}$helper $\mathrm{T}$ cells were gated on CD45RA$\mathrm{CXCR}^{+}$circulating TfH cells. Lastly, CCR6 and CXCR3 surface expression were determined from this gated TfH cells. 


\section{Statistical Analysis}

All data are presented as mean \pm Standard Deviation (SD) values. Statistical analysis was conducted with GraphPad Prism 5 software (San Diego, CA, USA). The Mann-Whitney U-test was used for between-group comparisons of continuous variables and categorical variables between groups [sex (male vs female)] were compared using Fisher's exact test. The Spearman's rank correlation test was performed for correlation analysis. Results were considered significant when $p<0.05$.

\section{Results}

\section{Allergy Markers and TfH Subsets in Pediatric Patients with Allergic Disorders}

No significant differences were observed between the non-allergy and allergy groups in age and sex ratios. Allergy markers, such as total IgE and serum TARC levels and Eo\%, were significantly higher in the allergy group than in the non-allergy group (Fig. 3 upper). Further, no differences were observed in the percentage of TfH2 (TfH2\%), TfH1 (TfH1\%) and TfH17 (TfH17\%) cells in the total $\mathrm{TfH}$ cell repertoire between the allergy and non-allergy groups (Fig. 3 lower).

Since IgE levels vary through adolescence, we divided the allergy group into three subgroups: 0-2 years of age (infants), 3-5 years (preschool) and 6 years and more (school-aged children). In the infant subgroup (Fig. 4A), no significant difference was observed in both the allergic markers (total IgE levels, Eo\% and TARC levels) and in TfH cell subsets (Tfh1\%, Tfh2\% and Tfh17\%), although IgE levels appeared higher in the allergy group than in the control group. In the preschool group (Fig. 4B), Eo\% was significantly higher in the allergy group than in the control group $(p<0.05)$. However, IgE and TARC levels did not significantly differ. Furthermore, no significant difference was observed in $\mathrm{TfH}$ subsets. Among schoolaged children (Fig. 4C), IgE levels and Eo\% were significantly higher in the allergy group than in the control group. Furthermore, TARC levels did not significantly differ. Moreover, the $\mathrm{TfH} 2 \%$ was significantly lower in the allergy group than in the non-allergy group.

\section{Correlation Between IgE Levels and TfH Subsets}

Fig. 5 shows the correlation between IgE levels and $\mathrm{TfH}$ subsets. In the non-allergy group, a weak negative correlation was observed between IgE levels and $\mathrm{TfH} 2 \% \quad(\mathrm{r}=0.522)$. No correlation was observed between IgE levels and $\mathrm{TfH} 1 \%$ or $\mathrm{TfH} 17 \%$. In the allergy group, $\mathrm{TfH} 2 \%$ as well as $\mathrm{TfH} 1 \%$ and $\mathrm{TfH} 17 \%$ was not significantly correlated with $\operatorname{IgE}$ levels. Furthermore, no correlations were observed between IgE levels and TfH2/TfH1 cells or (TfH2+TfH17)/TfH1 cells (Fig. 6).
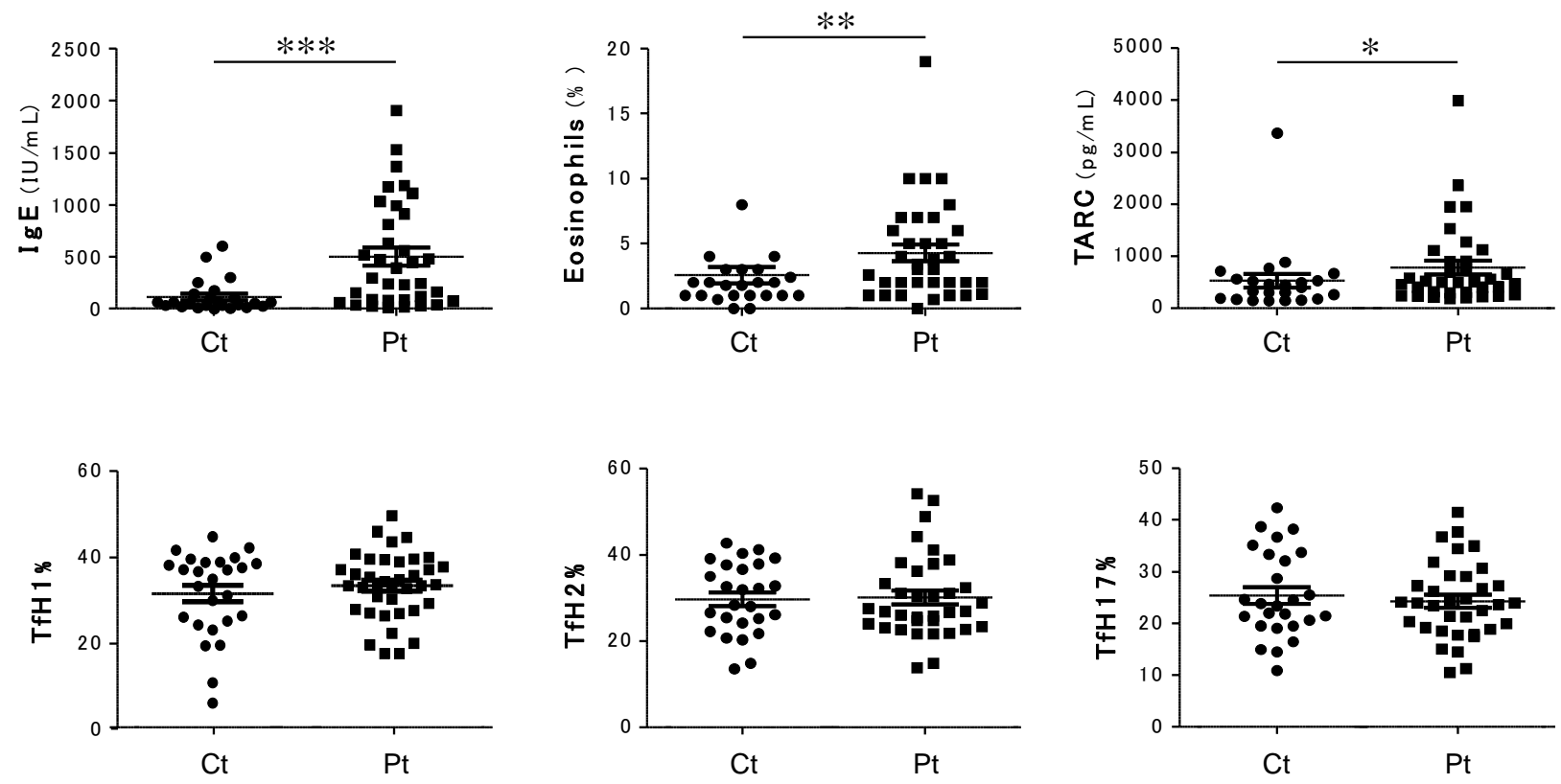

Fig. 3: Allergy markers and TfH subset skewing. Ct: Control (Non-allergy) group, Pt: Patient (Allergy) group. ${ }^{*} p<0.05, * * p<0.01$, $* * * p<0.001$ 
A
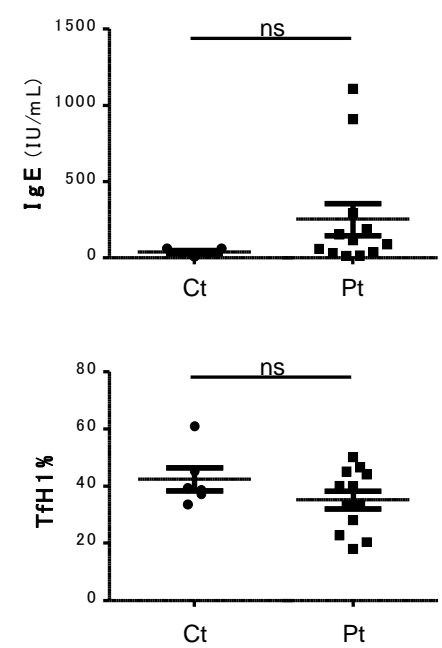

B
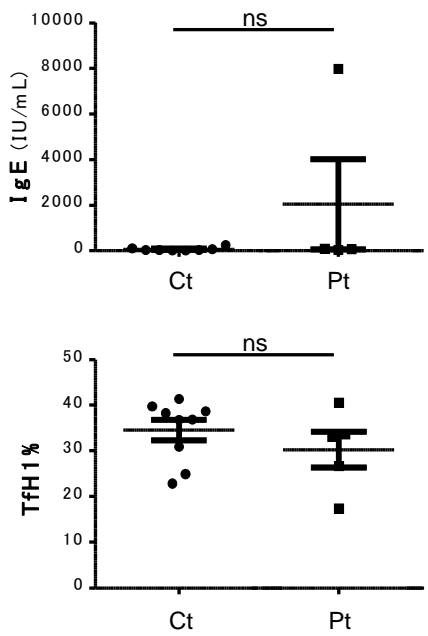

C
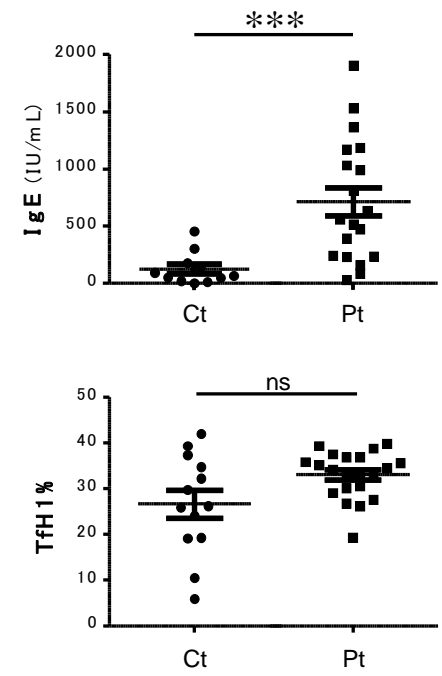
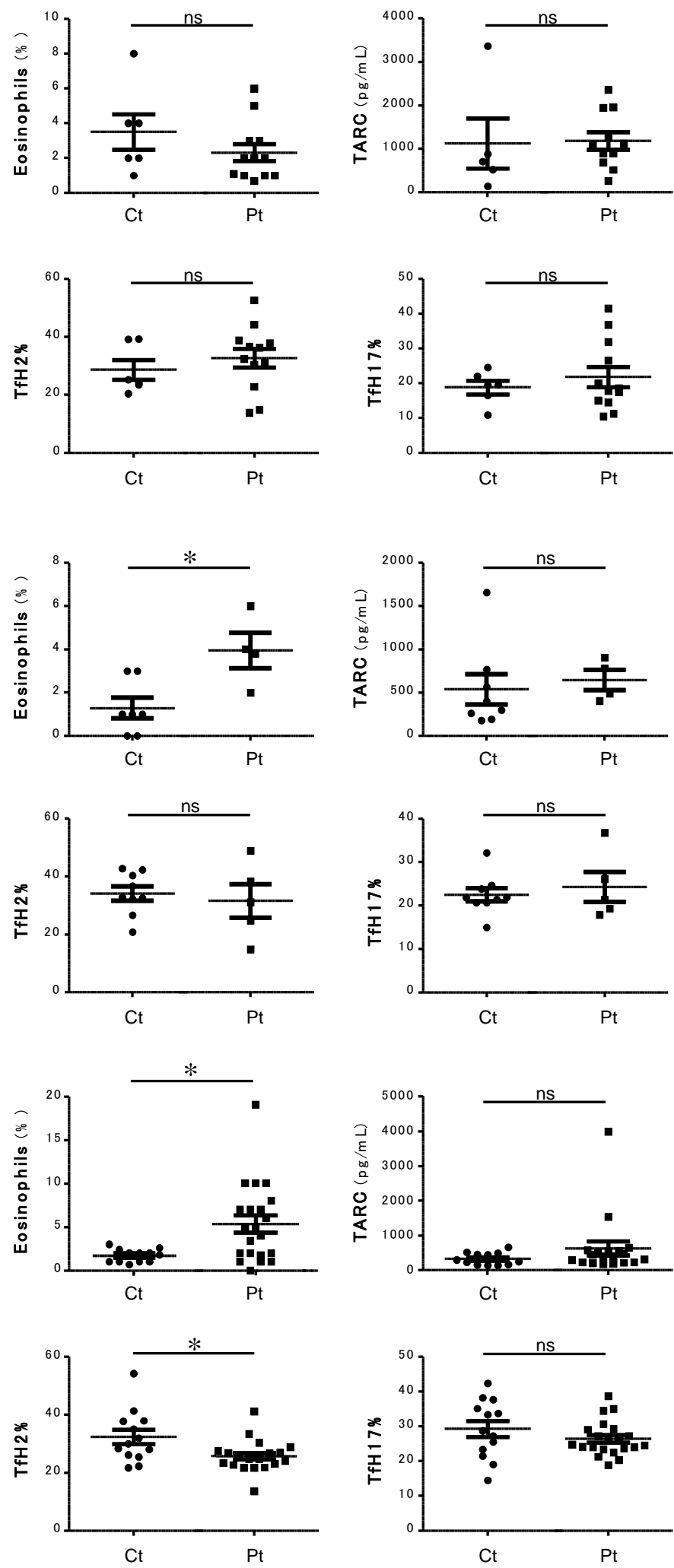

Fig. 4: Allergy markers and TfH subsets skewing by age group. (A) infants, (B) preschool and (C) school-aged children. Ct: Control (Non-allergy) group, Pt: Patient (Allergy) group. ns: Not significant, $* p<0.05, * * * p<0.001$ 

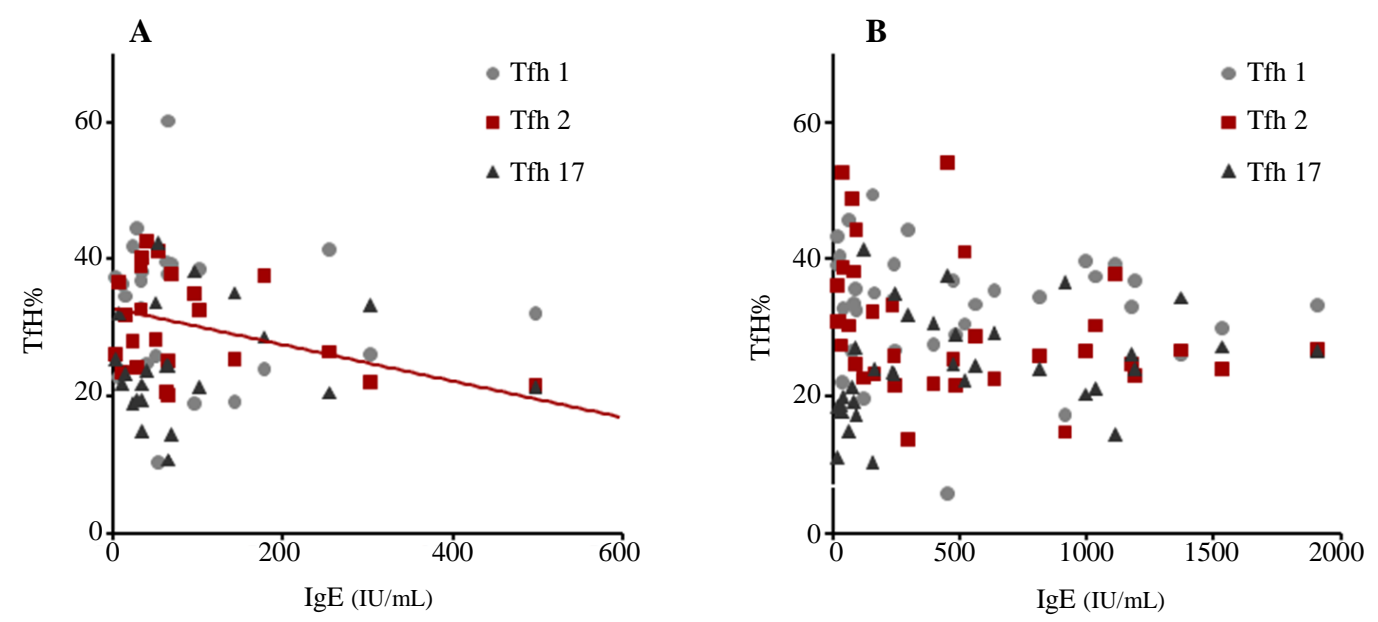

Fig. 5: Correlation between IgE levels and TfH subsets. (A) Control (Non-allergy) group. (B) Patient (Allergy) group
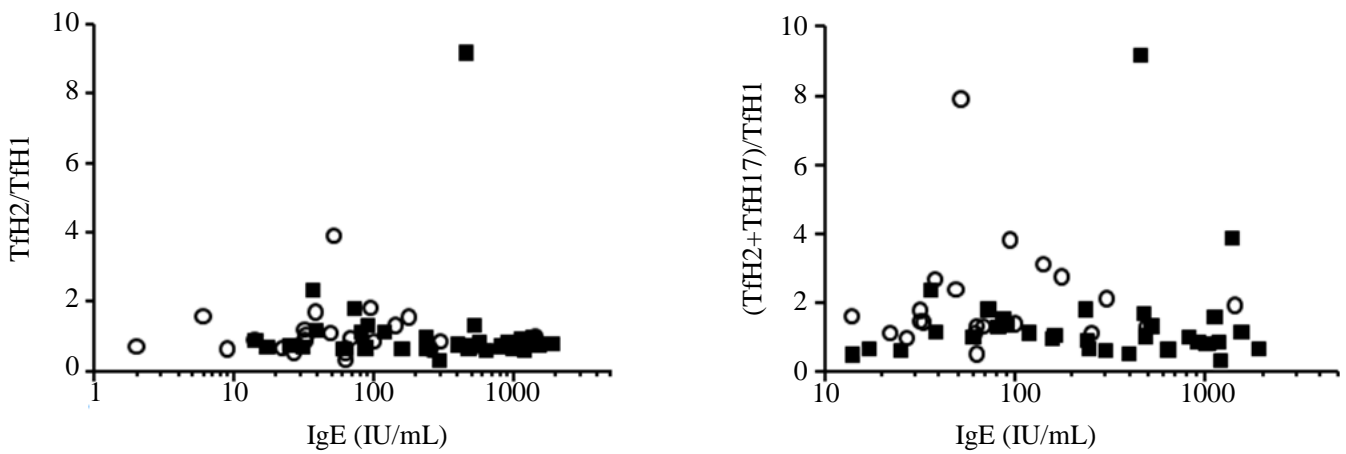

Fig. 6: Correlation between IgE levels and TfH2/TfH1 or (TfH2+TfH17)/TfH1. (A) Correlation between IgE levels and TfH2/TfH1. (B) Correlation between IgE levels and (TfH2+TfH17)/TfH1. Note that the X axis is in log scale. Open circle: Control (Nonallergy) group. Closed square: Patient (Allergy) group

\section{Discussion}

In this study, we failed to demonstrate a shift toward $\mathrm{TfH} 2$ dominance in peripheral blood in pediatric allergy patients, contrary to our hypothesis of $\mathrm{TfH} 2$ polarization within TfH subsets. Furthermore, in the school-aged children, $\mathrm{TfH} 2 \%$ was significantly lower in the allergy group than in the non-allergy group; however, the underlying reason remains unclear. These findings suggest the occurrence of limited changes in peripheral blood TfH 2 cells in pediatric allergic diseases. Although we observed that the percentage of blood $\mathrm{TfH} 2$ cells decreases with an increase in IgE levels, its significance is obscure because this phenomenon was observed only in the non-allergy group wherein $\operatorname{IgE}$ levels were almost within normal ranges.

We analyzed three subsets of TfH cells (TfH1, TfH2 and TfH17) in accordance with previous studies. Most recently, Gowthaman et al. (2019) reported that Tfh13, which can produce IL-4 and IL-13, is the primary TfH cell subset contributing to high-affinity antigen-specific
IgE production, while $\mathrm{TfH} 2$ potentially accounts for total IgE production. Furthermore, they reported that the number of circulating TfH13 cells expressing BCL6 and GATA3 is elevated in allergy patients (Gowthaman et al., 2019). Our results would not challenge the TfH13 hypothesis (Xie and Dent, 2019). Further studies are required to clarify the role of TfH13 cells in pediatric allergies.

In this study, there were concerns regarding the heterogeneity of individuals in the non-allergic group, which comprised sick children with several disease types and healthy children. However, since the present results displayed a significant difference in IgE levels between the allergy and non-allergy groups, we believe that the composition of the non-allergic group was appropriate for this study; thus, the between-group comparisons yielded valid results. Nevertheless, this study has several limitations, including the small number of participants. Patients in the allergic group had comorbid pleural allergic diseases, which is one of the characteristics of pediatric allergies with atopic march (Aw et al., 2020), although atopic dermatitis was dominant. Since atopic 
dermatitis is a complex disease involving both innate and adaptive immune responses (Ghosh et al., 2018), the role of $\mathrm{TfH} 2$ cells might be less important in atopic dermatitis. Furthermore, the allergy group comprised patients with varying degrees of disease severity, which might have influenced our results. Moreover, some allergy patients received antihistamine therapy, which might have also affected the results. Despite these limitations, our study provides insights into the mechanism underlying $\operatorname{IgE}$ maintenance in pediatric allergy patients from the viewpoint of $\mathrm{TfH}$ cells.

\section{Conclusion}

In this study, we hypothesized that a $\mathrm{TfH} 2$ shift in peripheral blood maintains elevated $\operatorname{IgE}$ levels in pediatric allergy patients; however, we did not observed $\mathrm{TfH} 2$ skewing in pediatric allergy patients. Our results raised further questions to be explored, including whether peripheral blood $\mathrm{TfH}$ reflects the dynamics of $\mathrm{TfH}$ in the lymphoid follicles and whether TfH13 cells are involved in elevating IgE levels in pediatric patients. Further studies are required to elucidate the long-term $\operatorname{IgE}$ productionpromoting mechanism in pediatric allergy patients.

\section{Funding Information}

This research did not receive any specific grant from funding agencies in the public, commercial, or not-forprofit sectors.

\section{Author's Contributions}

MH Masaaki Hamada: Collected blood samples, performed laboratory studies, analyzed data and drafted the manuscript.

Yoshihiko Sakurai: Designed the study, interpreted the data and edited the manuscript.

Tomohiro Takeda: Designed the study, performed flow cytometric analysis, analyzed data and edited the manuscript.

\section{Ethics}

This article is original and contains unpublished material. The corresponding author confirms that all of the other authors have read and approved the manuscript and there are no ethical issues involved.

\section{References}

Arakawa, H., Y. Hamasaki, Y. Kohno, M. Ebisawa and N. Kondo et al., 2017. Japanese guidelines for childhood asthma. Allergol. Int., 66: 190-204.

DOI: 10.1016/j.alit.2016.11.003
Aw, M., J. Penn, G.M. Gauvreau, H. Lima and R. Sehmi, 2020. Atopic March: Collegium internationale allergologicum update. Int. Archives Allergy Immunol., 181: 1-10. DOI: $10.1159 / 000502958$

Brunner, P.M., A. Israel, N. Zhang, A. Leonard and H.C. Wen et al., 2018. Early-onset pediatric atopic dermatitis is characterized by $\mathrm{T}_{\mathrm{H}} 2 / \mathrm{T}_{\mathrm{H}} 17 / \mathrm{T}_{\mathrm{H}} 22-$ centered inflammation and lipid alterations. J. Allergy Clin. Immunol., 141: 2094-2106. DOI: $10.1016 /$ j.jaci.2018.02.040

Ebisawa, M., K. Ito and T. Fujisawa, 2017. Committee for japanese pediatric guideline for food allergy, the japanese society of pediatric allergy and clinical immunology and the japanese society of allergology. Japanese guidelines for food allergy. Allergol. Int., 66: 248-264.

DOI: 10.1016/j.alit.2017.02.001

Ghosh, D., J.A. Bernstein, G.K. Khurana Hershey, M.E. Rothenberg and T.B. Mersha, 2018. Leveraging multilayered "Omics" data for atopic dermatitis: A road map to precision medicine. Frontiers Immunol., 9: 2727-2727. DOI: 10.3389/fimmu.2018.02727

Gong, F., C. Qian, H. Zhu, J. Zhu and Y. Pan et al., 2016. Circulating follicular T-helper cell subset distribution in patients with asthma. Allergy Asthma Proc., 37: 154-161. DOI: 10.2500/aap.2016.37.3982

Gong, F., H.Y. Zhu, J. Zhu, Q.J. Dong and X. Huang, et al., 2018. Circulating $\mathrm{CXCR}^{+} \mathrm{CD} 4^{+} \mathrm{T}$ cells participate in the $\mathrm{IgE}$ accumulation in allergic asthma. Immunol. Lett., 197: 9-14.

DOI: 10.1016/j.imlet.2018.03.001

Gong, F., Q. Su, D. Jiang, J. Chen and Y. Pan et al., 2014. High frequency of circulating follicular helper $\mathrm{T}$ cells in patients with bronchial asthma. Clínica Laboratorio, 60: 963-968. DOI: 10.7754/clin.lab.2013.130427

Gowthaman, U., J.S. Chen, B. Zhang, W.F. Flynn and Y. Lu et al., 2019. Identification of a T follicular helper cell subset that drives anaphylactic IgE. Science, 365: 6456-6456. DOI: 10.1126/science.aaw6433

Harada, Y., S. Tanaka and Y. Motomura, 2012. The 3' enhancer CNS2 is a critical regulator of interleukin4-mediated humoral immunity in follicular helper $\mathrm{T}$ cells. Immunity, 36: 188-200.

DOI: 10.1016/j.immuni.2012.02.002

Illi, S., E. von Mutius, S. Lau, B. Niggemann and C. Gruber et al., 2006. Perennial allergen sensitisation early in life and chronic asthma in children: A birth cohort study. Lancet, 368: 763-770. DOI: $10.1016 / \mathrm{S} 0140-6736(06) 69286-6$

Izquierdo-Dominguez, A., I. Jauregui, A. Del Cuvillo, J. Montoro and I. Davila et al., 2017. Allergy rhinitis: Similarities and differences between children and adults. Rhinology, 55: 326-331. DOI: $10.4193 /$ Rhin17.074 
Kasperkiewicz, M., E. Schmidt, R.J. Ludwig and D. Zillikens, 2018. Targeting IgE antibodies by immunoadsorption in atopic dermatitis. Frontiers Immunol., 9: 254-254.

DOI: $10.3389 /$ fimmu.2018.00254

Kobayashi, T., K. Iijima, A.L. Dent and H. Kita, 2017. Follicular helper $\mathrm{T}$ cells mediate $\mathrm{IgE}$ antibody response to airborne allergens. J. Allergy Clin. Immunol., 139: 300-313. DOI: e307.10.1016/j.jaci.2016.04.021

Kubo, M., 2017. T follicular helper and $\mathrm{TH}_{2}$ cells in allergic responses. Allergol. Int., 66: 377-381.

DOI: 10.1016/j.alit.2017.04.006

Larsen, G.L., 2000. Differences between adult and childhood asthma. J. Allergy Clin. Immunol., 106: S153-S157. DOI: 10.1067/mai.2000.109421

Lebman, D.A. and R.L. Coffman, 1988. Interleukin 4 causes isotype switching to $\mathrm{IgE}$ in $\mathrm{T}$ cell-stimulated clonal B cell cultures. J. Exp. Med., 168: 853-862. DOI: $10.1084 /$ jem.168.3.853

Morita, R., N. Schmitt, S.E. Bentebibel, R. Ranganathan and L. Bourdery et al., 2011. Human blood $\mathrm{CXCR}^{5+} \mathrm{CD}^{4+} \mathrm{T}$ cells are counterparts of $\mathrm{T}$ follicular cells and contain specific subsets that differentially support antibody secretion. Immunity, 34: 108-121. DOI: 10.1016/j.immuni.2010.12.012

Nurieva, R.I., Y. Chung, G.J. Martinez, X.O. Yang and S. Tanaka et al., 2009. Bcl6 mediates the development of $\mathrm{T}$ follicular helper cells. Science, 325: 1001-1005. DOI: 10.1126/science. 1176676

Poulsen, L.K. and L. Hummelshoj, 2007. Triggers of IgE class switching and allergy development. Annals Med., 39: 440-456.

DOI: $10.1080 / 07853890701449354$
Saeki, H., T. Nakahara, A. Tanaka, K. Kabashima and M. Sugaya et al., 2016. Clinical practice guidelines for the management of atopic dermatitis. J. Dermatol., 43: 1117-1145. DOI: $10.1111 / 1346-8138.13392$

Szabo, K., K. Gaspar, Z. Dajnoki, G. Papp and B. Fabos et al., 2017. Expansion of circulating follicular $\mathrm{T}$ helper cells associates with disease severity in childhood atopic dermatitis. Immunol. Lett., 189: 101-108. DOI: 10.1016/j.imlet.2017.04.010

Ueno, H., J. Banchereau and C.G. Vinuesa, 2015. Pathophysiology of $\mathrm{T}$ follicular helper cells in humans and mice. Nature Immunol., 16: 142-152. DOI: $10.1038 /$ ni.3054

Vijayanand, P., G. Seumois, L.J. Simpson, S. AbdulWajid and D. Baumjohann et al., 2012. Interleukin4 production by follicular helper $\mathrm{T}$ cells requires the conserved Il4 enhancer hypersensitivity site V. Immunity, 36: 175-187.

DOI: $10.1016 /$ j.immuni.2011.12.014

Waserman, S., P. Begin and W. Watson, 2018. IgEmediated food allergy. Allergy Asthma Clin. Immunol., 14: 55-55. DOI: $10.1186 / \mathrm{s} 13223-018-0284-3$

Xie, M.M. and A.L. Dent, 2019. Interleukin-13 Is unlucky for allergy sufferers. Trends Pharmacol. Sci., 40: 714-716. DOI: 10.1016/j.tips.2019.08.007

Zhang, Y.N., J. Song, H. Wang, H. Wang and M. Zeng et al., 2016. Nasal $\mathrm{IL}_{-}{ }^{4+} \mathrm{CXCR}^{5+} \mathrm{CD}^{4+} \mathrm{T}$ follicular helper cell counts correlate with local $\mathrm{IgE}$ production in eosinophilic nasal polyps. J. Allergy Clin. Immunol., 137: 462-473.

DOI: $10.1016 /$ j.jaci.2015.07.025 